British Journal of Ophthalmology, 1986, 70, 47-54

\title{
Minnesota system corneal preservation
}

\author{
RICHARD L LINDSTROM, DONALD J DOUGHMAN, DEBRA L SKELNIK, \\ AND ELIZABETH A MINDRUP
}

\author{
From the University of Minnesota, USA Department of Ophthalmology
}

SUMmARY The clinical and laboratory results with a modified Minnesota system of organ culture corneal preservation are presented. A refinement of our preservation technique using a closed system, as well as the addition of chondroitin sulphate to the medium is presented. Laboratory results show preservation of corneal endothelial integrity for at least 21 days with maintenance of normal corneal thickness. In addition, a 10-day quarantine system reduces the risk of donor contamination and secondary endophthalmitis. Preliminary results of the $34^{\circ} \mathrm{C}$ and $4^{\circ} \mathrm{C}$ closed Minnesota corneal preservation system using chondroitin sulphate show that it is safe and efficacious and allows intermediate to long-term maintenance of sterile thin tissue prior to corneal transplantation.

The success of penetrating keratoplasty in humans depends primarily on transplanting an adequate amount of viable donor endothelium. ' Therefore any method used to store the donor cornea must maintain endothelial viability. Techniques for preservation of corneas prior to transplant currently include $4^{\circ} \mathrm{C}$ moist chamber refrigeration of the whole globe, ${ }^{2}$ storage at $4^{\circ} \mathrm{C}$ in TC-199 with dextran (MK media), ${ }^{3}$ and cryopreservation. ${ }^{4}$ Each of these techniques, while serving a useful purpose, has significant limitations. A progressive loss of endothelial cells occurs at $4^{\circ} \mathrm{C}$ storage in both whole globe and MK storage techniques. ${ }^{25}$ This limits the duration of storage to less than 96 h. ${ }^{5-7}$ Cryopreservation allows a storage time of at least one year but it is a complex technology limited to a few centres and has a significant primary donor endothelial failure rate. ${ }^{48}$

At the University of Minnesota we have been investigating $34^{\circ} \mathrm{C}$ organ culture of the cornea as a preservation technique since 1972 (Minnesota system) and have previously reported our results. ${ }^{9-20}$ Although these studies confirm that human corneas can be successfully transplanted after five weeks of storage, three problems have limited the general acceptance of this method. First is the need to develop a system which assures sterility of donor tissue stored by this method. Secondly, the donor tissue thickens during storage, reducing the surgeon's

Correspondence to Richard L Lindstrom, MD, University of Minnesota, Department of Ophthalmology, Box 493 Mayo Memorial Building, 516 Delaware Street SE, Minneapolis, MN 55455, USA. acceptance of this tissue. Thirdly, the standard organ culture method is technically complicated and expensive.

This paper reports our approach to solving the problems of sterility, thick donor tissue, and system complexity.

\section{Materials and methods}

For the past four years we have used a simpler closed system $34^{\circ} \mathrm{C}$ organ culture storage method. This system has significantly reduced complexity and expense and allows an adequate sterility check to be performed prior to transplantation. In this system corneas are suspended from a spinal needle inserted through the scleral rim in a $100-150 \mathrm{ml}$ volume of medium and stored at $34^{\circ} \mathrm{C}$ for up to four weeks prior to transplantation without changing the medium. The current organ culture medium is shown in Table 1.

In one technique on day 1 the excised corneas are placed in $34^{\circ} \mathrm{C}$ open organ culture with gentamycin sulphate $(90 \mu \mathrm{g} / \mathrm{ml})$ as the only antibiotic present. On day 3 the corneas are transferred to another $34^{\circ} \mathrm{C}$ open organ culture without antibiotics, and on day 6 the corneas are suspended in the $34^{\circ} \mathrm{C}$ closed organ culture bottle (Fig. 1). In another technique the corneas are immediately placed in the closed system bottles. On day 5-7 of closed system storage $10 \mathrm{ml}$ of the medium is removed from the bottle and plated for microbiological evaluation. The medium is evaluated for sterility under anaerobic conditions at $30^{\circ} \mathrm{C}$ and 
Table 1 Minnesotasystem medium

Minimum essential medium (Eagle's) with 25 mM HEPES buffer

Earle's salts without L-glutamine

L-glutamine $-1 \%$ final concentration

Decomplemented calf serum ( $5 \%$ final concentration)

Fetal calf serum ( $5 \%$ final concentration)

$1.5 \%$ chondroitin sulphate $(50000 \mathrm{MW})$

$90 \mu \mathrm{g} / \mathrm{ml}$ gentamicin sulphate

anaerobic conditions at $35^{\circ} \mathrm{C}$. In addition, fungal cultures are done on Sabouraud's agar plates stored at $30^{\circ} \mathrm{C}$. The bottles containing the corneas as well as the plates and media are examined daily for evidence of contamination. If after 7-10 days no growth is noted on any of the microbiological media, and the medium in the closed bottles containing the corneas is clear without $\mathrm{pH}$ change, the system is considered sterile and the corneas may be transplanted. For $4^{\circ} \mathrm{C}$ closed system storage the corneas are placed in $20-150 \mathrm{ml}$ of media and then in a refrigerator to transplantation.

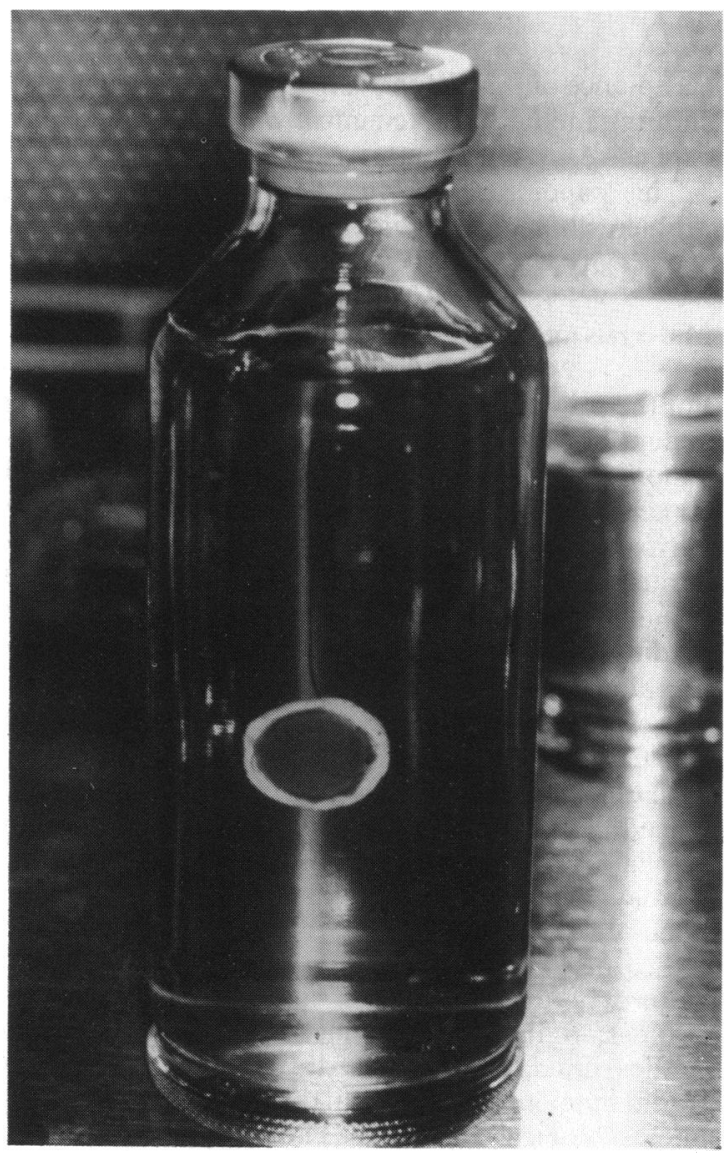

Fig. 1 Cornea stored in the closed Minnesota system bottle.

\section{Laboratory and clinical evaluation}

Studies were performed to evaluate the safety and efficacy of $34^{\circ} \mathrm{C}$ and $4^{\circ} \mathrm{C}$ closed Minnesota system organ culture. Clinical results were evaluated in regard to tissue sterility. Cat and human corneas were studied after preservation by ultrasonic pachymetry for corneal thickness, vital staining of the corneal endothelium with alizarin red $\mathrm{S}$ and trypan blue for cell maintenance, endothelial specular microscopy, and through primary transplantation. High molecular weight dextran (approx. 500000 $\mathrm{MW}$ ) and chondroitin sulphate (approx. $50000 \mathrm{MW}$ ) were evaluated for their safety and efficacy in maintaining corneal deturgescence.

The first problem to be assessed was the ability of the closed system to allow reasonable assurance of donor tissue sterility. Between 1 January 1982 and 20 February 1984 over 400 organ culture corneas have been transplanted after $34^{\circ} \mathrm{C}$ Minnesota system storage. No cases of fungal or bacterial endophthalmitis have occurred since the new sterility routine has been in place.

The second problem of the original open system was thickening of corneal tissue during storage. Corneas may be thinned after $34^{\circ} \mathrm{C}$ Minnesota system storage by immersion of the cornea for 6-12 hours in a hyperosmotic solution such as in TC-199 with 5\% dextran (MK medium). This, however, requires breaking the sterility quarantine prior to transplantation and may lead to endothelial cell loss. For this reason attempts were made to maintain corneal deturgescence during culture.

Initially high molecular weight dextran (500 000 MW) was used during organ culture in an attempt to maintain corneal deturgescence. Eight human corneas and 20 cat corneas stored for 21 to 28 days were examined after closed system organ culture using $1-5 \%$ high molecular weight dextran as an additive. The effectiveness of the corneal thinning was found to be proportional to the concentration of high molecular weight dextran. Concentrations of $5 \%$ dextran were found to be effective in maintaining corneal deturgescence in the cat and human cornea. Concentrations of high molecular weight dextran greater than $5 \%$ resulted in some precipitation of the dextran in the medium. Unfortunately, while dextran at concentrations of $5 \%$ yielded effective corneal deturgescence, the corneal endothelium showed extensive vacuolization of the cytoplasm and ingestion of the dextran on transmission electron microscopy (Fig. 2). At dextran concentrations as high as $8 \%$ areas of Descemet's membrane were devoid of endothelial cells, suggesting cell death. It was concluded that, while high molecular weight dextran at concentrations of approximately $5 \%$ were effective 


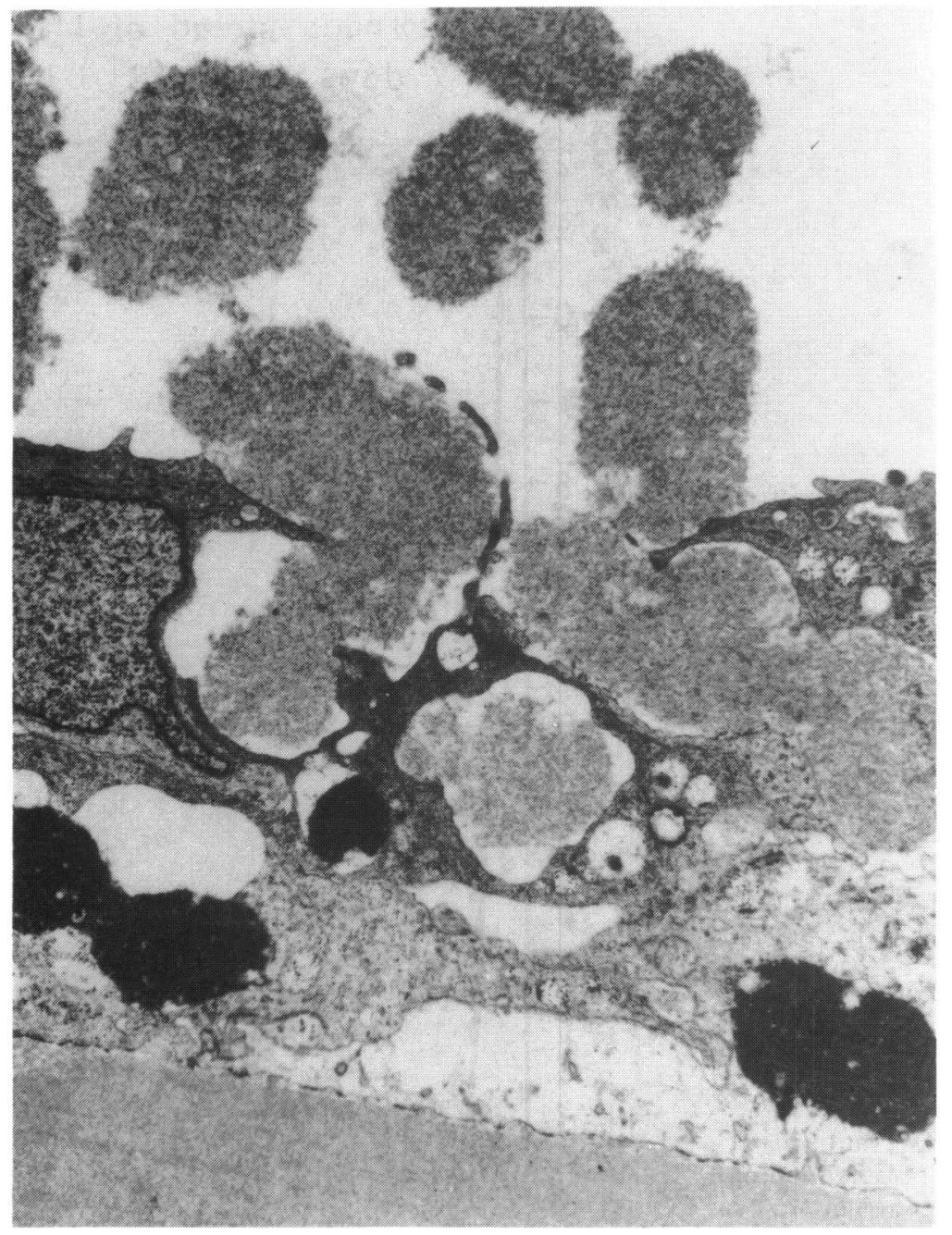

Fig. 2 Human corneal endothelium stored for four weeks in organ culture media containing $5 \%$ dextran shows significant dextran ingestion and vacuolisation on transmission electron microscopy. $(\times 15$ 400).

in maintaining corneal deturgescence, they may be toxic to the corneal endothelium during long-term corneal preservation at $34^{\circ} \mathrm{C}$.

Several other substances, including mannitol, urea, glycerol, polyvinylpyrolidone, and lower molecular weight dextrans were evaluated. None of these were found to be safe and effective during longterm corneal preservation.

Since 1982 the results of a technique using approximately 50000 molecular weight chondroitin sulphate have been examined. A dose response curve for maintenance of corneal deturgescence in both cats and humans was evaluated in a range from $1 \%$ to $3.5 \%$ at $4^{\circ} \mathrm{C}$ on $34^{\circ} \mathrm{C}$. In the human cornea a chondroitin sulphate concentration of $1.5 \%$ appeared to maintain normal corneal thickness dur- ing preservation for 30 days (Fig. 3 ). In the cat cornea a concentration of $2 \cdot 0-2 \cdot 5 \%$ was required to maintain normal corneal thickness at 30 days, and this concentration was effective at $4^{\circ} \mathrm{C}$ and $34^{\circ} \mathrm{C}$ (Figs. 4 and 5).

Six cat corneas were then preserved for four weeks in $34^{\circ} \mathrm{C}$ closed system organ culture using $2 \%$ and $3 \%$ chondroitin sulphate, and they showed a normal endothelial mosaic by vital staining. Twelve more cat corneas were then transplanted after preservation in $34^{\circ} \mathrm{C}$ closed Minnesota system organ culture with chondroitin sulphate. Each transplant resulted in clear graft. Fig. 6 shows a clear transplant in a cat cornea and Fig. 7 the accompanying prestorage and postoperative central specular photomicrographs. The medium containing chondroitin sulphate has 


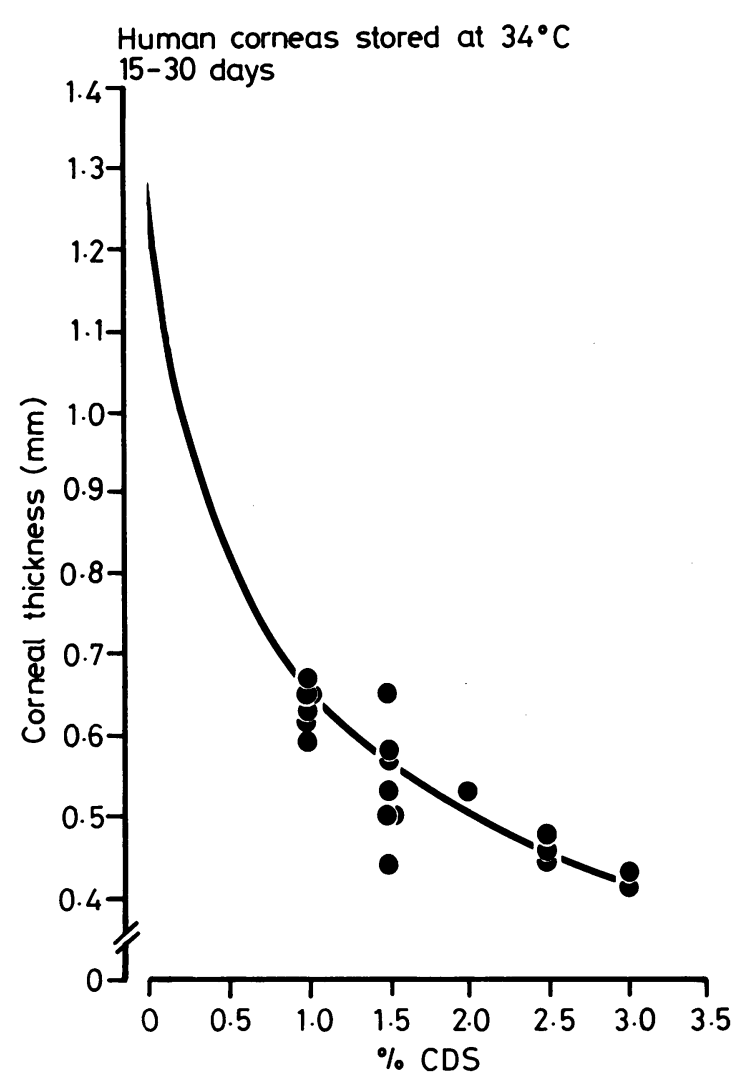

Fig. 3 Dose response curve for $50000 \mathrm{MW}$ medium containing chondroitin sulphate during $34^{\circ} \mathrm{C}$ Minnesota system storage of the human cornea for 15-30 days.

also been evaluated for corneal preservation at $4^{\circ} \mathrm{C}$, and our preliminary studies show preservation of a normal appearing endothelial mosaic in the cat cornea for at least three weeks (Fig. 8) and in the human cornea for one week (Fig. 9).

So far 84 patients have received corneal transplants using corneas stored for $15-30$ days in $34^{\circ} \mathrm{C}$ closed Minnesota system organ culture with chondroitin sulphate. Some corneal thickening has been noted in corneas stored over 14 days. Follow-up ranges from three weeks to one year. There have been no primary donor failures. Seven of the donor corneas have been evaluated through endothelial cell counts of the peripheral rim after trephination. After storage of 21-28 days the endothelial cell counts ranged from 2142 to 2666 , with a mean of 2330 cells $/ \mathrm{mm}$. ${ }^{2}$ One patient has undergone postoperative specular microscopy centrally at six weeks, with an endothelial cell count of 2775 cells $/ \mathrm{mm}^{2}$ (Fig. 10). Evaluation of the donor rim endothelium in this patient following trephination also confirms excellent endothelial cell preservation (Fig. 10).

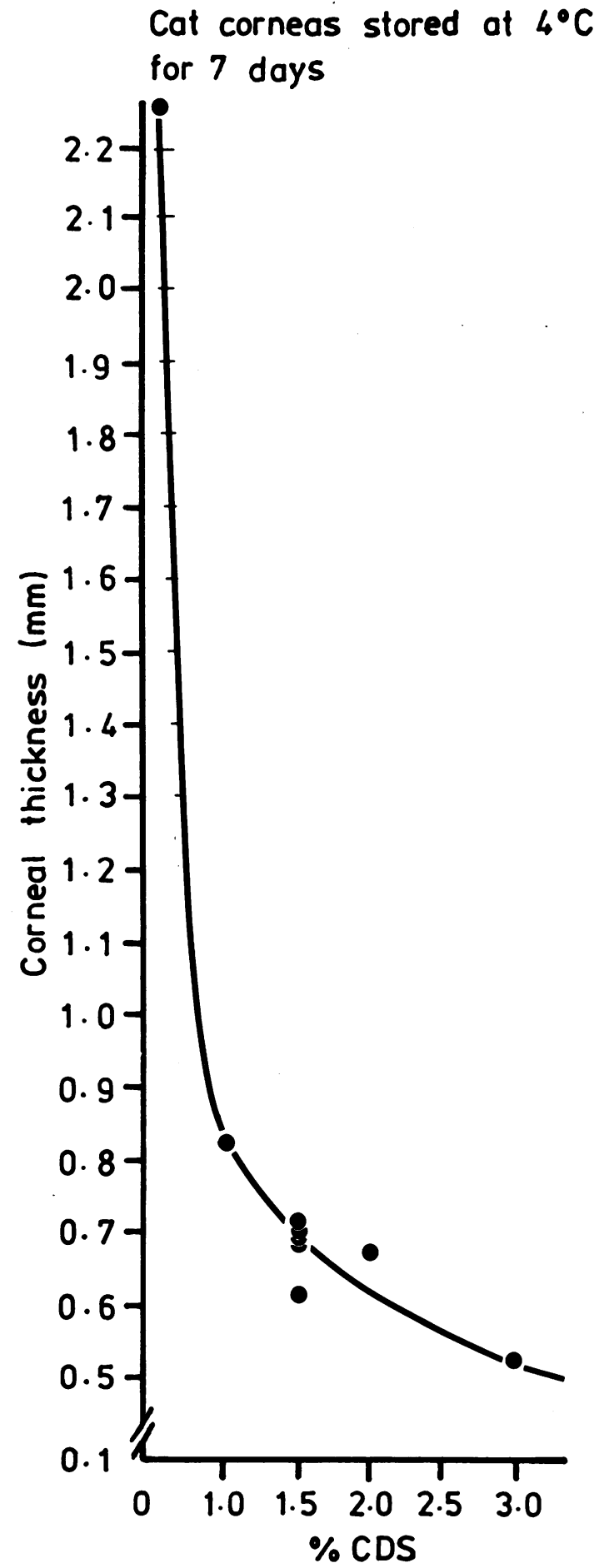

Fig. 4 Dose response curve for $50000 \mathrm{MW}$ medium containing chondroitin sulphate during $4^{\circ} \mathrm{C}$ Minnesota system storage of the cat cornea for seven days. 


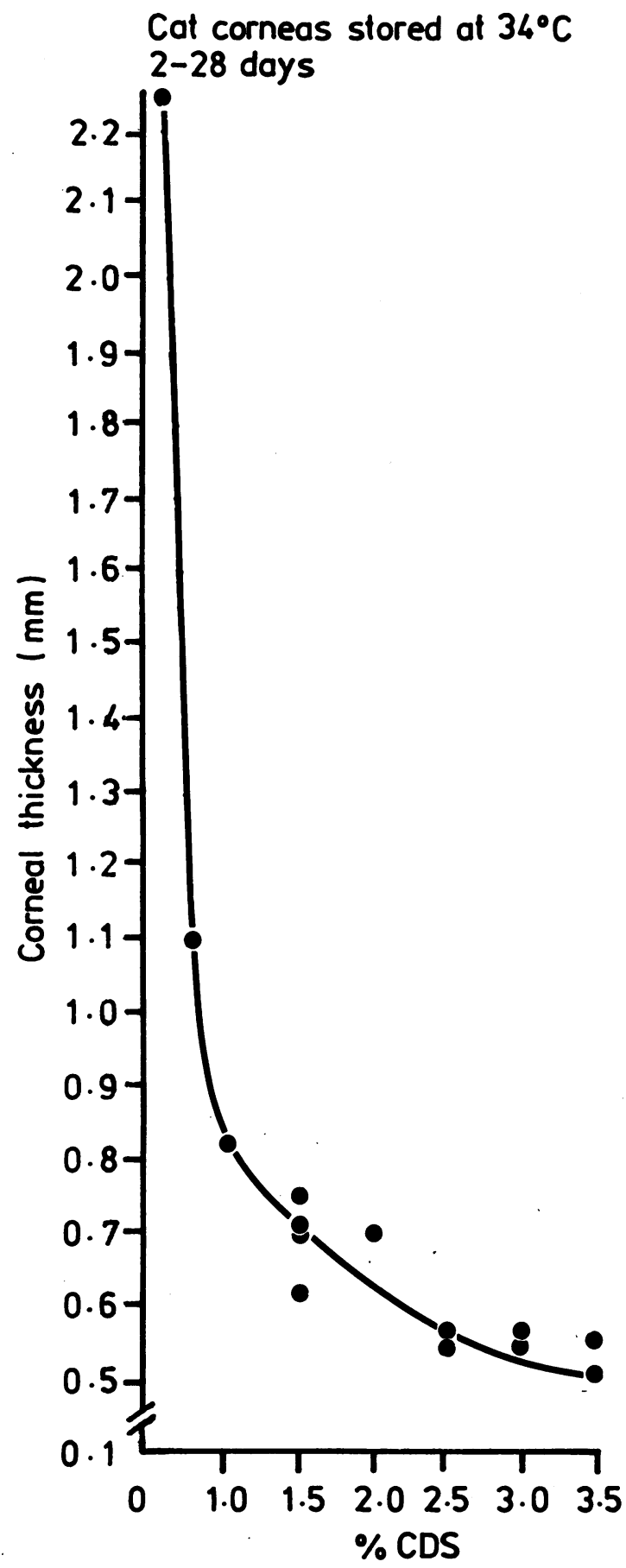

Fig. 5 Dose response curve for $50000 \mathrm{MW}$ medium containing condroitin sulphate during $34^{\circ} \mathrm{C}$ Minnesota system storage of the cat cornea for 2-28 days.

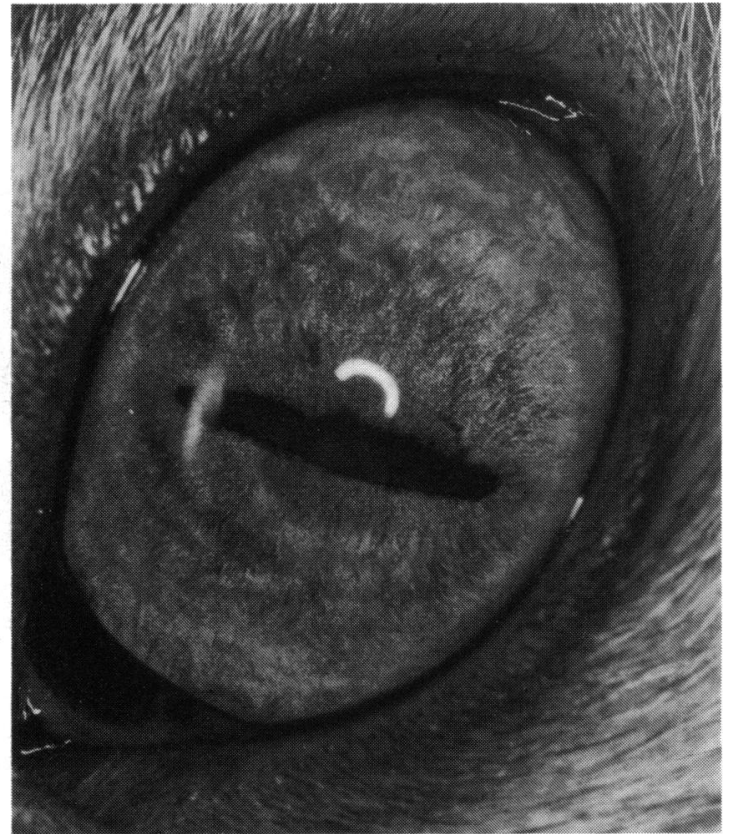

Fig. 6 Postoperative appearance of a cat. Homograft three months postoperative using a cornea stored in $34^{\circ} \mathrm{C}$ closed Minnesota system with $2 \cdot 5 \%$ chondroitin sulphate for 16 days.

\section{Discussion}

Our previous laboratory and clinical experience has convinced us that $34^{\circ} \mathrm{C}$ Minnesota system organ culture was a satisfactory technique for corneal preservation. ${ }^{220}$ We have therefore increased our efforts to solve the three primary remaining problems, namely, sterility of the tissue, maintenance of corneal deturgescence during preservation, and simplification of the technique.

Since switching to the closed system with a twoweek quarantine no cases of endophthalmitis have been noted in over 400 cases. The incidence of endophthalmitis following keratoplasty with MK stored tissue in one large study has been reported as $0 \cdot 2 \% .{ }^{21}$ While the incidence of endophthalmitis can never be reduced to zero, we consider that our results of over 400 keratoplasties with no care of graft contamination reassures us that this system provides satisfactory control of sterility.

The addition of chondroitin sulphate to the medium reduces the problem of corneal thickening during Minnesota system organ culture preservation at both $4^{\circ} \mathrm{C}$ and $34^{\circ} \mathrm{C}$. This may allow the use of a single universal medium for storage of corneas from one to seven days at $4^{\circ} \mathrm{C}$ or as long as three to four weeks at $34^{\circ} \mathrm{C}$ with excellent endothelial preservation 


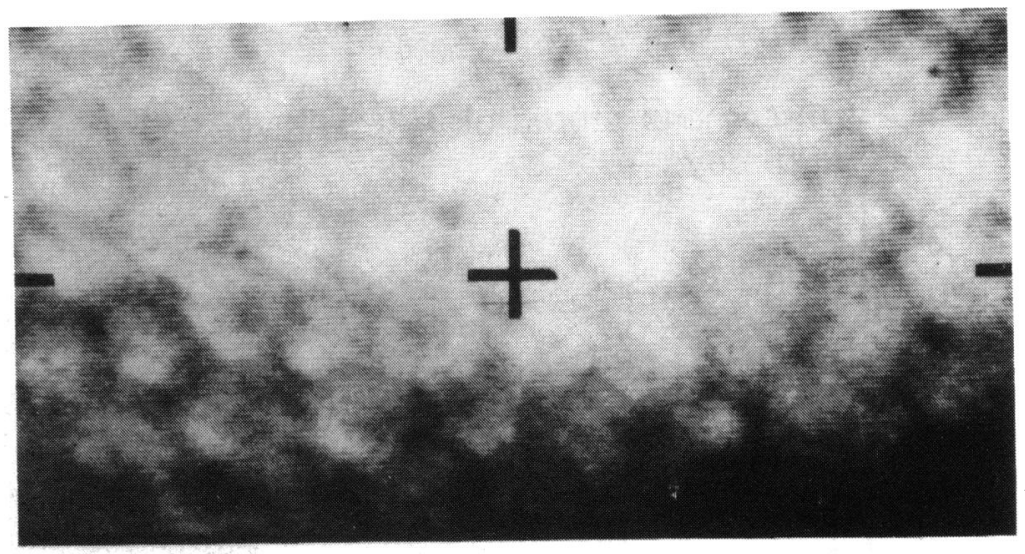

Fig. 7 Prestorage and three month postoperative central corneal endothelial specular photomicrographs of the donor cornea in Fig. 5. The prestorage cell count is 2800 cells $/ \mathrm{mm}^{2}$ and the three month postoperative cell count is 2500 cells $/ \mathrm{mm}^{2}$
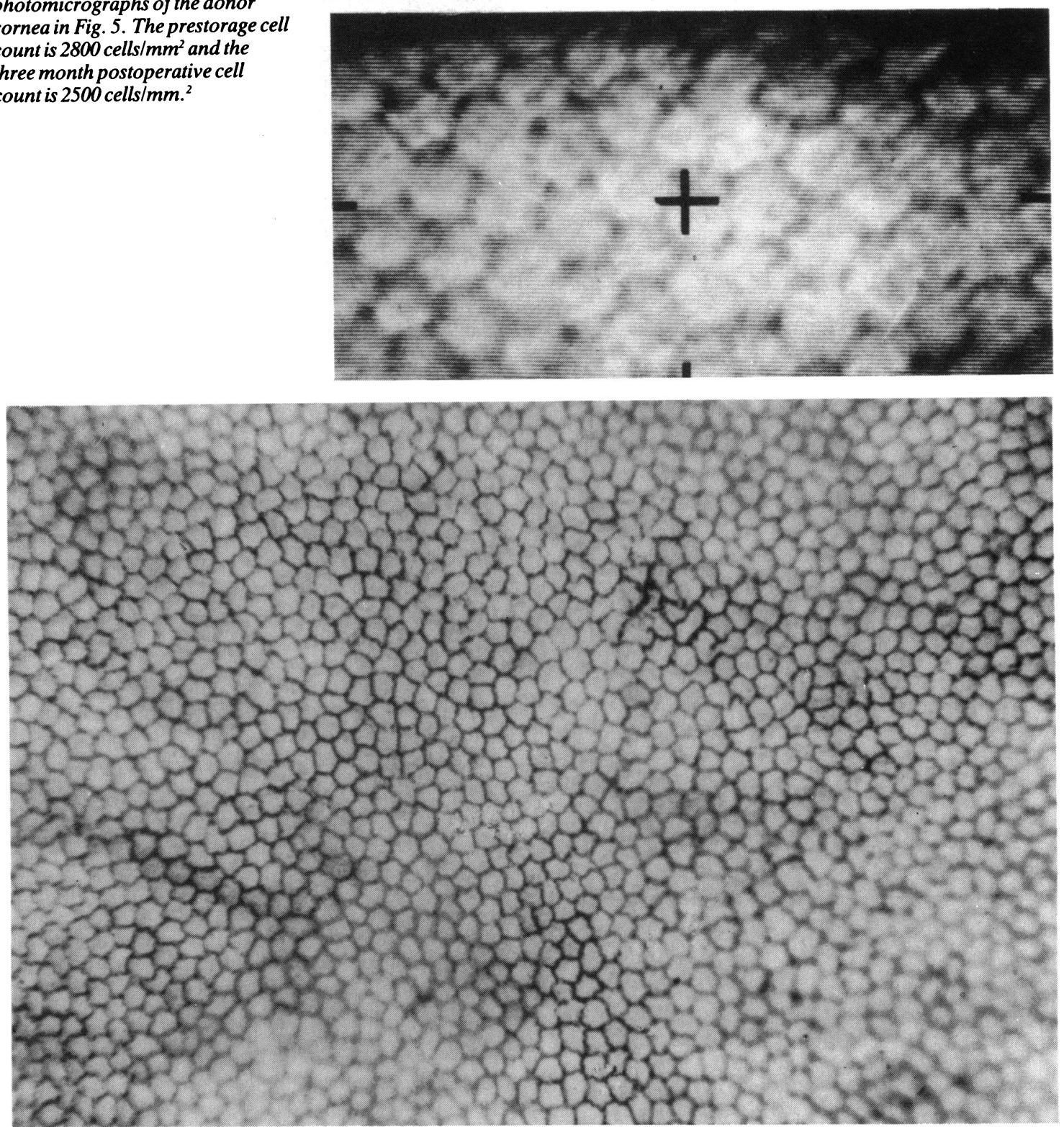

Fig. 8 Endothelial mosaic of the cat cornea after three weeks' storage in $4^{\circ} \mathrm{C}$ closed Minnesota system with $2.5 \%$ chondroitin sulphate. 


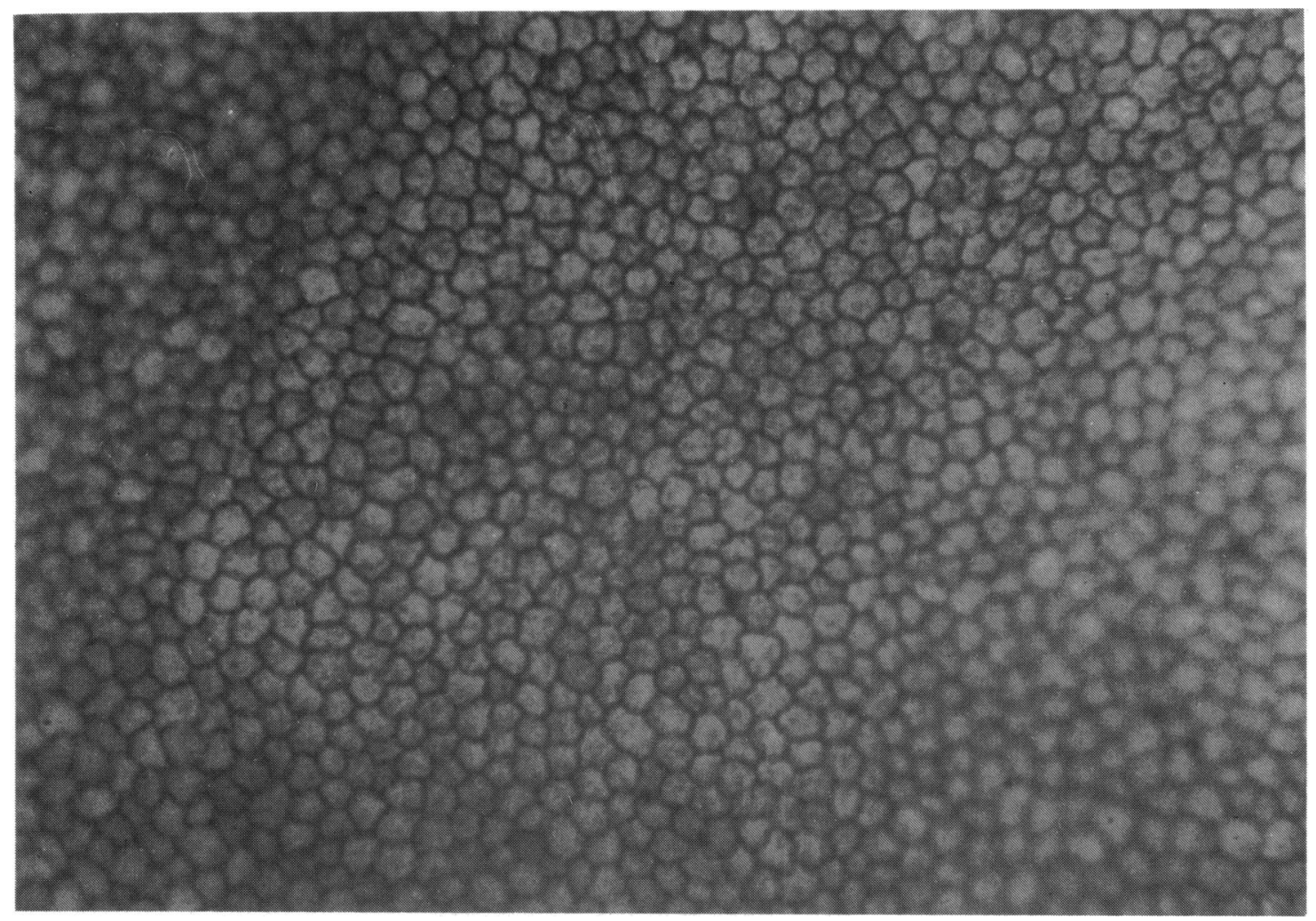

Fig. 9 Endothelial mosaic of the human cornea following seven days' storage in $4^{\circ} \mathrm{C}$ closed Minnesota system with $1 \cdot 5 \%$ chondroitin sulphate.

and more normal corneal thickness. Use of this medium in the closed system also significantly simplifies the technique, reducing expense and complexity.

The results of this research indicate that $34^{\circ} \mathrm{C}$ and $4^{\circ} \mathrm{C}$ closed Minnesota system corneal preservation is safe and effective for intermediate term storage of donor corneas prior to human transplantation. The closed system allows a quarantine to ensure tissue sterility and simplifies the system. The addition of chondroitin sulphate to the medium provides a cornea of more normal thickness. We consider these improvements make the system more useful for corneal preservation. We are now continuing a careful prospective evaluation of endothelial viability and survival following penetrating keratoplasty.

This work was supported in part by an unrestricted grant from Research to Prevent Blindness, Inc.

\section{References}

1 Stocker RW. The endothelium of the cornea and its clinical implications. Trans Am Ophthalmol Soc 1953; 51: 669-786.

2 Slappey TE. Corneal preservation. Transplant Proc 1976; 8(suppl 1): 223-17.
3 McCarey BF. Corneal storage and handling. In: Kaufman HE, Zimmerman TJ, eds. Current concepts in ophthalmology. St Louis: Mosby, 1976; 134-63.

4 Capella JA, Kaufman HE. Corneal cryopreservation and its clinical application. In: Casey TA, ed. Corneal grafting. London: Butterworth, 1972; 219-32.

5 Aquavella JV, Van Horn DL, Haggerty CJ. Corneal preservation using M-K media. Am J Ophthalmol 1975; 80: 791-9.

6 Bigar F, Kaufman HE, McCarey BE, Binder PS. Improved corneal storage for penetrating keratoplasties in man. Am J Ophthalmol 1975; 79: 115-20.

7 Stark WJ, Maumanee AE, Kenyon KR. Intermediate-term corneal storage for penetrating keratoplasty. Am J Ophthalmol 1975; 79: 795-802.

8 Kaufman HE. Corneal cryopreservation and its clinical application. Transplant Proc 1976; 8: (suppl 1): 149-52.

9 Bourne W, Doughman DJ, Lindstrom RL. Organ cultured corneal endothelium in vivo. Arch Ophthalmol 1977; 95: $1818-9$.

10 Doughman DJ. Prolonged donor corneal storage in organ culture: long term clinical evaluation. Trans Am Ophthalmol Soc 1980; 78: $567-628$.

11 Doughman DJ, Van Horn DL, Harris JE, Miller GE, Lindstrom RL, Summerlin W, Good RA. Endothelium of the organ cultured cornea; an electron microscopic study. Trans Am Ophthalmol Soc 1973; 71: 304-28.

12 Doughman DJ, Van Horn DL, Harris JE, Miller GE, Lindstrom $\mathrm{RL}$, Good RA. The ultrastructure of human organ cultured cornea. I. Endothelium. Arch Ophthalmol 1974; 92: 516-23. 
Fig. 10 Six week postoperative central corneal endothelial specular photomicrograph of a human donor cornea preserved in $34^{\circ} \mathrm{C}$ closed Minnesota system with $1.5 \%$ chondroitin sulphate for 15 days. The cell count is 2775 cells $/ \mathrm{mm}^{2}{ }^{2}$ Below is the endothelial mosaic of the donor rim after trephination.

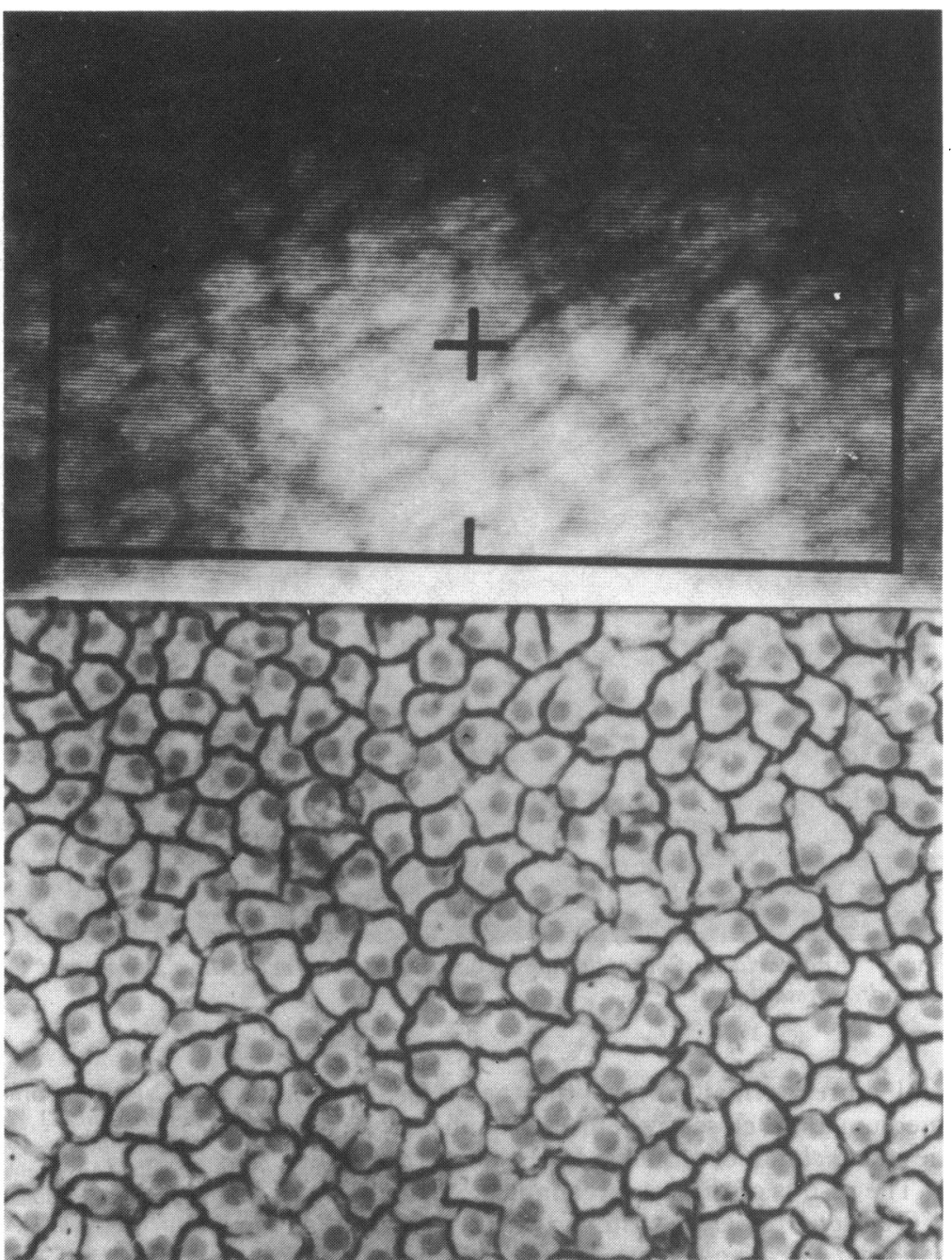

13 Doughman DJ, Van Horn DL, Rodman W, Byrnes P, Lindstrom RL. Human corneal endothelial layer repair during organ culture. Arch Ophthalmol 1976; 94: 1791-6.

14 Doughman DJ, Miller GE, Mindrup EA, Schmitt MK, Harris JE, Good RA. The fate of experimental organ cultured corneal xenografts. Transplantation 1976; 22: 132-7.

15 Doughman DJ, Harris JE, Schmitt MK. Penetrating keratoplasty using $37^{\circ} \mathrm{C}$ organ cultured corneas. Ophthalmology (Rochester) 1976; 81: 778-93.

16 Larson PA, Lindstrom RL, Doughman DJ. Torulopsis glabrata endophthalmitis after keratoplasty with an organ cultured cornea. Arch Ophthalmol 1978; 96: 1019-22.

17 Van Horn DL, Doughman DJ, Harris JE, Miller GE, Lindstrom RL, Good RA. The ultrastructure of human organ cultured cornea. II. Stroma and epithelium. Arch Ophthalmol 1975; 93: 275-7.

18 Nelson JD, Mindrup EA, Chung CK, Lindstrom RL, Doughman DJ. Fungal contamination in organ culture. Arch Ophthalmol 1983; 101: 280-83.

19 Doughman DJ, Harris JE, Mindrup EA, Lindstrom RL. Prolonged donor cornea preservation in organ culture. Cornea 1982; 1: 7-20.

20 Lindstrom RL, Doughman DJ, Mindrup EA. Penetrating keratoplasty following intermediate term organ culture corneal preservation at $37^{\circ} \mathrm{C}$. Fortschr Ophthalmol 1983; 80: 468-71.

21 Leveille AS, McMullan FD, Cavanagh HD. Endophthalmitis following penetrating keratoplasty. Ophthalmology (Rochester) 1983; 90: 38-9.

Accepted for publication 25 April 1985. 